\title{
Úlceras de pressão: prevenção e tratamento
}

\author{
Carlos Eduardo Maciel de Moura ${ }^{I}$ \\ Luciana Leite Melo e Silva ${ }^{2}$ \\ José Roberto P. de Godoy ${ }^{3}$
}

\begin{abstract}
RESUMO - Úlceras de pressão, de decúbito ou "escaras" são lesões que acometem o tecido cutâneo, levando à sua destruição parcial ou total. São comuns em pacientes acamados por longo período e privados de movimentos, ocasionando um quadro de compressão, lesão isquêmica e conseqüente destruição tecidual. A prevenção é a melhor forma de evitar o surgimento desse tipo de lesão, e medidas simples podem ser implementadas. O tratamento é com auxílio de medicamentos tópicos, utilizados após limpeza completa do ferimento, controle do estado nutricional do paciente e aplicações com laser de baixa intensidade que aceleram a cicatrização da lesão.
\end{abstract}

Palavras-chave: lesões cutâneas, úlceras de pressão, laser.

\section{Pressure ulcers: prevention and treatment}

\begin{abstract}
Pressure ulcers, decubits or "pressure sores" are lesions that attack the cutaneous tissue, taking to your partial or total destruction. They are common in patients fallen ill by a long period and private of movements, causing a compression picture, ischemic lesion and consequent tissue destruction. The prevention is still the best form of avoiding the appearance of that type of lesion and simple measures can be implemented. The treatment occurs with aid of topical medicines, used after cleaning it completes of the wound; controls of the patient's nutritional state and applications with laser of low intensity that accelerate the lesion's cicatrization.
\end{abstract}

Key words: cutaneous lesions, pressure ulcers, laser.

\footnotetext{
${ }^{1}$ Acadêmico do $7^{\circ}$ semestre docurso deFisioterapia do do Centro de Ensino Unificadode Brasília-UniCEUB E-mail:carlomd2@yahoo.com.br

${ }^{2}$ Acadêmica do $9^{\circ}$ semestre do curso de Fisioterapia do UniCEUB.E-mail: lu.lmeloesilva@ brturbo.com.br ${ }^{3}$ Mestre em Ciências da Saúde pela UnB; doutorando em Ciências da Saúde pela UFRN, professor de AnatomiaeNeuroanatomia doUniCEUB.E-mail: jose62521@uniceub.br
}

Univ. Ci. Saúde, Brasília, v. 3, n. 2, p. 275-286, jul./dez. 2005 
As úlceras de pressão são lesões cutâneas que surgem em resposta à falta de irrigação sanguínea adequada à agressão à pele que recobre a proeminência óssea nas zonas em que foi comprimida, friccionada ou arrastada contra uma cama, uma cadeira de rodas, uma tala ou outra estrutura rígida durante período prolongado ${ }^{1}$. Esses tipos de lesões mais comuns em pacientes acamados representam grande ameaça ao indivíduo, pois, além de causar desconforto, geram uma série de distúrbios no organismo, como a perda significativa de proteínas orgânicas, fluidos e eletrólitos. Isso pode levar a um quadro de debilidade progressiva com conseqüente baixa na resistência imunológica, o que pode possibilitar a entrada de microorganismos nocivos, como, por exemplo, estreptococos, estafilococos e Escherichia coli. Quando não fatais, essas infecções prolongam a doença e aumentam os dias de internação do paciente ${ }^{2}$.

Em pessoas normais, sem comprometimento vascular, observa-se que a pele é ricamente vascularizada. O grande aporte sangüíneo nesse tecido é suficiente para suprir a demanda de oxigênio necessária para o bom desempenho das células encontradas em todas as camadas. Se, por qualquer motivo, essa irrigação sangüínea for interrompida por mais de duas horas, o tecido passa a sofrer um mecanismo de hipóxia com conseqüente morte tecidual. As células encontradas na epiderme são as primeiras a serem lesadas já que o fluxo sangüíneo que as supre é normalmente precário. Uma das causas mais freqüentes do comprometimento da irrigação sangüínea da pele é a pressão ${ }^{3}$.

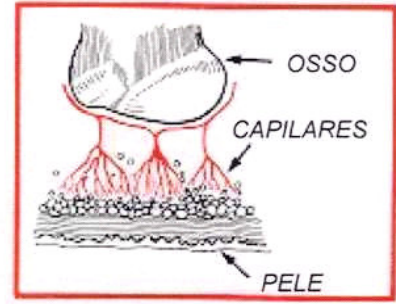

CAPILARES SEM EXCESSO DE PRESSÃO

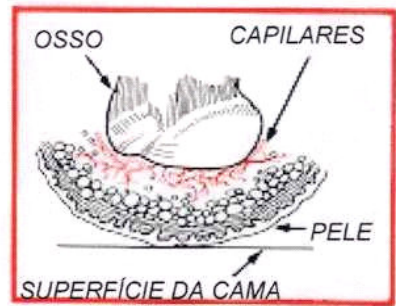

CAPILARES COM EXCESSO DE PRESSÃO

Figura 1: Diagramas dos capilares sem excesso de pressão e com excesso de pressão. Fonte: http://www.eerp.usp.br/projetos/ulcera/index.html

\footnotetext{
${ }^{1}$ http://www.manualmerck.net/?url=/artigos/\%3Fid\%3D223. ${ }^{2}$ SMELTZER \&BARE, 1994.

${ }^{3}$ http://www.manualmerck.net/?url=/artigos/\%3Fid\%3D223.
} 
Úlceras de pressão têm sido sinônimo de complicação para pacientes que permanecem muito tempo imobilizados em leito ou em cadeiras de rodas, portanto torna-se necessário ao fisioterapeuta o entendimento dos mecanismos que levam ao desenvolvimento deste tipo de lesão. Desta forma, este trabalho objetiva, por meio de revisão da literatura, relacionar os fatores de risco para o seu desenvolvimento, bem como as formas de prevenção, os tipos de tratamento e o papel da fisioterapia neste processo.

\section{Fatores de risco para úlceras de pressão}

As pessoas que se encontram impossibilitadas de locomover-se correm maior risco de desenvolver úlceras por pressão. Este grupo engloba pacientes plégicos, comatosos ou debilitados e confinados ao leito. As pessoas que apresentam algum grau de perda da sensibilidade tátil são sujeitas ao desenvolvimento desse tipo de úlcera uma vez que são incapazes de sentir incômodo ou dor, sinais comuns que induzem a mudança de posição e o conseqüente alívio da pressão $0^{4}$.

A fricção, que ocorre quando a pele do paciente sofre força de atrito contra a superfície na qual se encontra em contato, é um fator de risco importante para a instalação da úlcera de pressão. $\mathrm{O}$ atrito provoca o enfraquecimento do tecido epitelial uma vez que as células são perdidas com o movimento5.

Outro fator de risco é o cisalhamento, que é uma pressão excessiva exercida quando o paciente é movimentado, reposicionado ou transferido da cama e/ou cadeira. Quando o paciente é puxado ou quando se movimenta espontaneamente, tanto na cadeira quanto no leito, sua pele fixa à superfície de contato enquanto as camadas subcutâneas se deslocam no sentido do movimento do corpo ${ }^{6}$. Esse movimento acaba por desprender a pele dos tecidos subjacentes, provocando enfraquecimento e conseqüente ulceração.

O estado nutricional da pessoa é fator importantíssimo para o desenvolvimento de úlceras de pressão. Os pacientes que apresentam baixo peso, diminuição no nível de albumina sérica, baixa energia e ingestão diária inadequada de alimentos têm maior chance de desenvolver úlceras de pressão?

Outro fator que contribui para o surgimento das úlceras de pressão é a umidade. A pele pode encontrar-se úmida em conseqüência da sudorese excessiva do paciente, pela incontinência urinária, naqueles que apresentam disfunções vesicais, incontinência fecal ou a drenagem das feridas. A umidade excessiva e prolongada

${ }^{4}$ http://www. Manualmerck.net/?url=/artigos/\%3Fid\%3D223.

${ }^{5}$ BRYANT etal., 1992.

${ }^{6}$ HOODEDINCHER, 1995.

${ }^{7} \mathrm{http}: / /$ www.feridologo.com.br/fculceras.htm.

Univ. Ci. Saúde, Brasília, v. 3, n. 2, p. 275-286, jul./dez. 2005 
causa maceração da pele, reduzindo a resistência, o que a predispõe a traumas ${ }^{8}$.

O paciente com capacidade de percepção de estímulos comprometida, como, por exemplo, estímulos táteis, apresenta grandes chances de desenvolver úlcera de pressão. A sensibilidade cutânea diminuída interfere diretamente na percepção da dor. Uma pessoa que não apresenta essa capacidade preservada torna-se incapaz de perceber mudanças na pressão exercida sobre a pele ocasionada pelo mau posicionamento; dessa forma, fica impossibilitada de realizar mudanças de decúbito que aliviariam a pressão e, conseqüentemente, evitariam o quadro isquêmico que leva à ulceração?

No envelhecimento, diversas mudanças são observadas na pele e nas estruturas que lhe garantem suporte. Ocorre diminuição da massa corpórea, o que pode ser notada pelo aspecto enrugado da pele, pela diminuição da resposta inflamatória frente a lesões, pela redução na quantidade de fibras elásticas com conseqüente perda de tensão tecidual, pelo colágeno dérmico diminuído em quantidade e qualidade, pela diminuição do tecido adiposo subcutâneo. Os idosos têm diminuição no funcionamento de todos os sistemas corporais, o que leva à diminuição na capacidade vital e à conseqüente fragilidade. Dessa forma, vários pesquisadores apontam a idade avançada como fator de risco para o desenvolvimento de úlceras de pressão ${ }^{10}$.

\section{Classificação das úlceras de pressão}

As úlceras de pressão podem ser classificadas levando-se em conta o grau de destruição dos tecidos por elas atingidos. Quanto mais camadas teciduais são comprometidas, maior o grau de classificação da lesão. Hoje, verificam-se quatro graus para classificar as úlceras de pressão.

Essa classificação é útil quando se comparam os resultados obtidos pelos métodos de tratamento, embora se deva lembrar que as manifestações cutâneas das úlceras de pressão são somente a "ponta do iceberg". Ao mesmo tempo em que as alterações cutâneas ocorrem, a úlcera, no plano profundo, pode ser muito mais extensa, uma vez que, quanto mais profundo for o tecido, mais intensos são os efeitos da pressão, atingindo o máximo junto à proeminência óssea ${ }^{11}$.

Na úlcera de grau I, a pele encontra-se intacta, mas observa-se uma área eritematosa na região sob pressão; mesmo após o alívio da pressão, a região con-

\footnotetext{
${ }^{8}$ DEALEY, 1996.

${ }^{9}$ BRADENEBERGSTROM, 1987.

${ }^{10}$ DEALEY, 1996.

${ }^{11}$ COSTAFILHOetal., 1994.
} 
tinua hiperemiada. Outros sinais, como edema e calor, são evidenciados no local da lesão. Nas úlceras de grau II, já se evidencia a perda parcial da pele acometendo a epiderme, a derme ou ambas. A úlcera é superficial e apresenta-se como uma abrasão, uma bolha ou uma cratera rasa. As úlceras de grau III são lesões mais profundas, em que se observa a destruição completa de todas as camadas da pele com formação de uma cratera profunda e, por vezes, larga. A de grau IV, a mais severa de todas, compromete não só a pele como também músculos e tecido ósseo; nesse grau de lesão, o risco de complicação é elevado ${ }^{12}$.

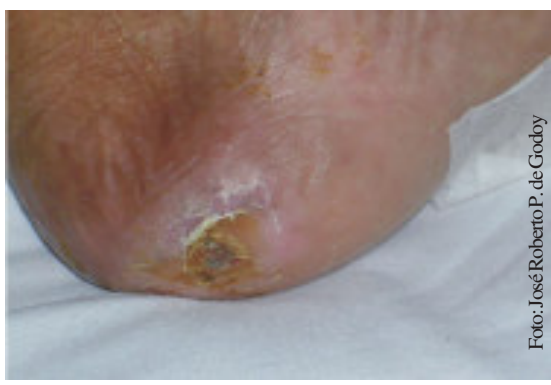

Foto 1: Úlcera de pressão: grau I

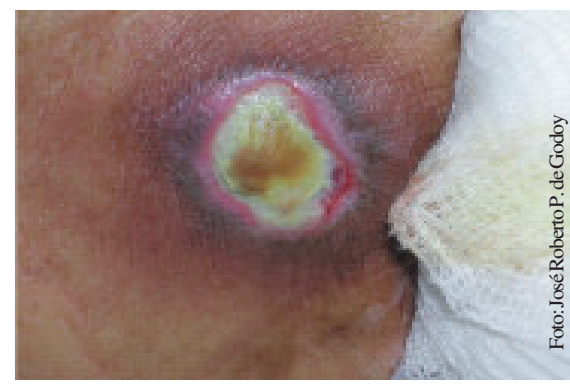

Foto 2: Úlcera de pressão: grau II

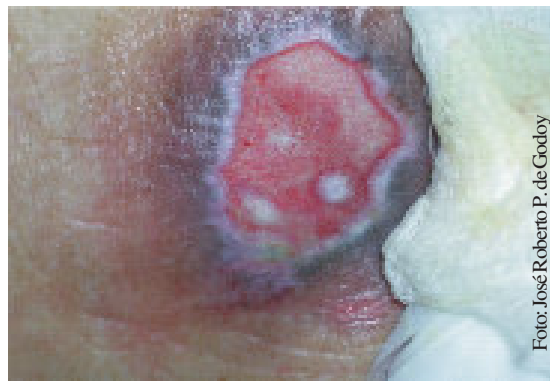

Foto 3: Úlcera de pressão: grau III

\section{Prevenção}

A prevenção é prioridade no controle das úlceras de pressão. As ulcerações profundas quase sempre podem ser evitadas adotando-se medidas simples, como, por exemplo, monitoramento constante da situação do paciente. Para a prevenção das úlceras de pressão ser eficaz, são fundamentais a participação e a

${ }^{12}$ BERGASTROM, 1992.

* Fonte: http://www.eerp.usp.br/projetos/feridas/tratpres.htm

Univ. Ci. Saúde, Brasília, v. 3, n. 2, p. 275-286, jul./dez. 2005 
cooperação mútua entre os profissionais da área de saúde e os familiares dos pacientes. A cuidadosa inspeção diária da pele dos pacientes acamados permite detectar os primeiros sinais de ulceração evidenciados pela vermelhidão local ${ }^{13}$.

A higiene corporal deve ser priorizada uma vez que, úmida, a pele torna-se mais sensível e suscetível a lesões. Outros cuidados diários, como a mobilização dos pacientes acamados (mudança de decúbito), pelo menos, a cada 2 horas e de hora em hora para os dependentes de cadeira de rodas, são importantes para prevenção. Devem-se usar travesseiros, toalhas e outros artifícios para apoiar tronco, membros superiores, sacro, nádegas e calcanhares (proeminências ósseas mais acometidas pelas úlceras) e equipamentos apropriados para prevenção, como colchão caixa de ovo, redutores de pressão, cadeiras especiais, almofadas e outros ${ }^{14}$.

É contra-indicado o uso de almofadas que apresentam orifício central, pois contribuem com o aumento da pressão glútea com conseqüente hipóxia tecidual, o que facilita a formação de escara nessa região. O paciente que permanece sentado por longos períodos deve levantar-se da cadeira a cada 15 minutos a fim de aliviar a pressão. Aqueles que não conseguem levantar-se devem ser auxiliados por outra pessoa ou levados de volta para a cama.

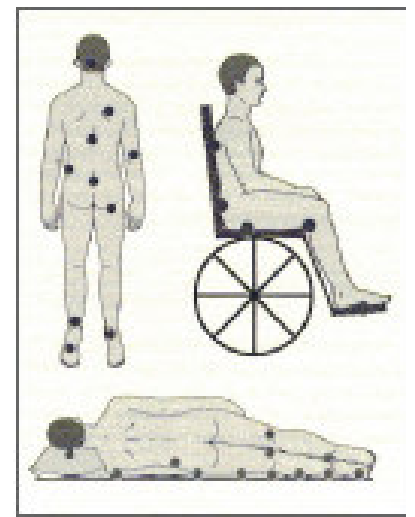

Figura 8 - Pontos acometidos por úlceras de pressão*

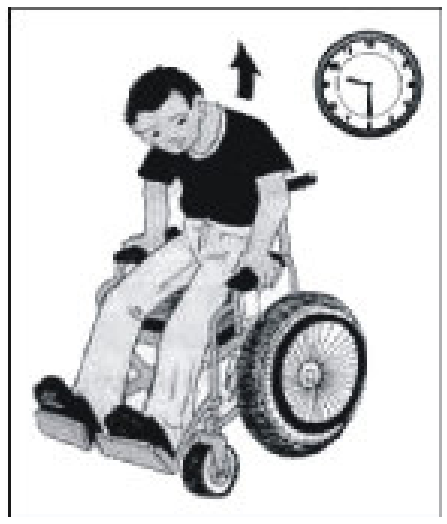

Figura 9 - Mudança de decúbito*

\footnotetext{
${ }^{13} \mathrm{http} / / / \mathrm{www}$. manualmerck.net/?url=/artigos/\%3Fid\%3D223.

${ }^{14}$ DEALEY, 2001.

*Fonte: Guia para prevenção de úlcera de pressão ou escara: orientação para pacientes adultos e famílias.
} 
Úlceras de pressão: prevenção e tratamento

\section{Tratamento convencional}

Para que se obtenha reparação tecidual satisfatória, é necessário favorecer condições locais por meio de terapia tópica adequada para viabilizar melhor cicatrização. A terapia tópica de feridas é fundamentada em estudos científicos sobre as diferentes fases presentes no processo de reparação tecidual e delineada pelos seguintes princípios: remover tecidos necróticos e corpos estranhos do leito da ferida, pois esse tipo de material favorece a contaminação do tecido e dificulta a reparação do tecido lesado. Deve-se, também, identificar e eliminar processos infecciosos, absorver o excesso de exsudato, manter a ferida limpa e seca, manter úmido o leito da ferida, promover isolamento térmico e proteger a ferida contra traumas e possíveis contaminações. A limpeza e a cobertura caracterizam as etapas da terapia tópica ${ }^{15}$.

\section{Limpeza}

A limpeza da ferida deve ser feita, de preferência, utilizando-se métodos que consistem na aplicação de líquidos anti-sépticos procurando minimizar o risco de trauma mecânico ou irritação da lesão. As soluções utilizadas na limpeza devem ser aquecidas previamente para que a temperatura nas bordas da ferida não seja reduzida. Acredita-se que uma temperatura próxima da temperatura corporal, ou seja, aproximadamente 37 graus, é ideal uma vez que estimula a multiplicação celular no local da lesão acelerando e otimizando as fases de cicatrização ${ }^{16}$.

A limpeza deve ser feita sempre no início da lesão e deve ser repetida quando da troca de curativos. Materiais, como gaze, compressas ou esponjas são os mais indicados uma vez que minimizam o trauma local e a lesão. Substâncias citotóxicas, como, por exemplo, água oxigenada ou solução à base de hipoclorito de sódio (líquido de Dakin) devem ser evitadas, pois sua ação química retarda o processo de proliferação celular. A utilização de solução salina a 0,9 \% é a mais indicada para a limpeza da maioria das úlceras de pressão. A pressão de irrigação deve ser empregada com seringas esterilizadas com agulhas que permitam alcançar a pressão de, aproximadamente, 4 a 15 libras por centímetro quadrado. Acredita-se que, abaixo desse valor, a pressão de irrigação seja insuficiente para a limpeza da ferida ${ }^{17}$.

${ }^{15}$ BLANES, 2004.

${ }^{16}$ BRYANT, 1992.

Univ. Ci. Saúde, Brasília, v. 3, n. 2, p. 275-286, jul./dez. 2005 


\section{Desbridamento}

O desbridamento é o processo pelo qual objetos estranhos e tecidos nãoviáveis são retirados do local da lesão, limpando-a no intuito de proporcionar ambiente ideal para a cicatrização ${ }^{18}$. O mais utilizado é o autolítico, que consiste no uso das enzimas encontradas no organismo humano para remover o tecido necrótico. Essa forma de desbridamento quase nunca provoca dor, o que o torna mais confortável e menos traumático. Tem a ação lenta, mas é bastante seletivo. Essa técnica é contra-indicada em caso de lesões infectadas, em grandes áreas de necrose e em pacientes imunodeprimidos. O desbridamento autolítico é conseguido utilizando-se hidrocolóides, hidrogel e filmes transparentes ${ }^{19}$.

\section{Papaína}

Nos últimos tempos, tem-se observado maior interesse por parte dos pesquisadores em relação à ação de enzimas proteolíticas no processo de limpeza de feridas infectadas, na retirada de material necrosado e na participação efetiva da recuperação do tecido lesado ${ }^{20}$.

Em experimento científico utilizando a papaína a 2\%, demonstrou-se que essa substância tem papel importante na reparação tecidual de lesões cutâneas uma vez que se observou melhora na fase de granulação da ferida com aumento local do número de fibroblastos e conseqüente melhora na produção e na deposição de fibras colágenas se comparada às lesões encontradas no grupo controle. A ação da papaína teve papel importante nas primeiras fases de remodelagem das lesões, garantindo melhor cicatrização $0^{21}$.

A solução de papaína a $2 \%$ tem sido utilizada no intuito de conseguir melhor granulação e maior epitelização da ferida; soluções a $10 \%$ são utilizadas no desbridamento de tecidos necrosados ${ }^{22}$. A papaína é utilizada no processo de amolecimento e remoção de tecido necrosado, particularmente em pacientes que se submeteram a procedimentos cirúrgicos ${ }^{23}$.

\footnotetext{
${ }^{17} \mathrm{http} / / / \mathrm{www} \cdot$ eerp.usp.br/projetos/ulcera/index.html.

18 YAMADA, 1999.

${ }^{19} \mathrm{http} / / / \mathrm{www}$. eerp.usp.br/projetos/feridas/tratpres.htm.

${ }^{20}$ MONETTA, 1987.

${ }^{21}$ SANCHEZetal.

${ }^{22}$ SILVA, 2003.

${ }^{23}$ SANCHEZetal.
} 
Úlceras de pressão: prevenção e tratamento

\section{Tratamento fisioterápico: laserterapia}

A origem da palavra laser surgiu da sigla inglesa "LASER" - "Light Amplification by Stimulated Emission of Radiation", ou seja, amplificação da luz por emissão estimulada de radiação ${ }^{24}$. O laser é constituído por ondas eletromagnéticas formadas por feixes de prótons paralelos entre si e com o mesmo comprimento de onda ${ }^{25}$.

Diversas formas de laser foram desenvolvidas nas últimas décadas. Alguns lasers de baixa potência são largamente empregados como técnicas terapêuticas, com o propósito de combater quadros álgicos e promover aceleração no processo de cicatrização, tanto no homem como nos animais, desde a década de 1960. A sua irradiação nos tecidos biológicos é estudada a fundo no intuito de descobrir os efeitos terapêuticos sobre os tecidos vivos ${ }^{26}$. Várias pesquisas demonstraram a viabilidade laserterapia, que, hoje, é aplicada no tratamento de feridas ${ }^{27}$.

Os estudos com seres vivos mostram que a regeneração de tecido torna-se mais eficaz quando da utilização de laser de baixa potência. Esse tipo de modalidade de irradiação age sobre a síntese de colágeno e sua remodelação e parece aumentar o número de fibroblastos atuantes na região lesada. Observam-se sinais de melhora na vascularização da lesão, evidenciada pela neoangiogênese. Efeitos antibacterianos e aumento da proteção imunológica também são evidenci$\operatorname{ados}^{28}$.

O laser de baixa potência tem sido empregado em vários experimentos científicos, porém não se encontra, na literatura, uniformidade quanto aos tipos utilizados e nem mesmo a dose mais efetiva ${ }^{29}$. A terapia com raios laser tem-se mostrado eficaz no controle da dor inflamatória e não inflamatória ${ }^{30}$. O laser tem ação analgésica uma vez que estudos demonstram que sua aplicação libera substâncias quimiotáxicas, induzindo a liberação de endorfinas, o que normaliza o potencial elétrico da membrana celular promovendo o efeito analgésico ${ }^{31}$.

A terapia com laser é indicada no tratamento de lesões cutâneas superficiais e profundas. Pode ser empregada, também, em lesões infectadas ${ }^{32}$. O laser de baixa potência tem ação antiinflamatória local, pois melhora a reabsorção de exsudatos

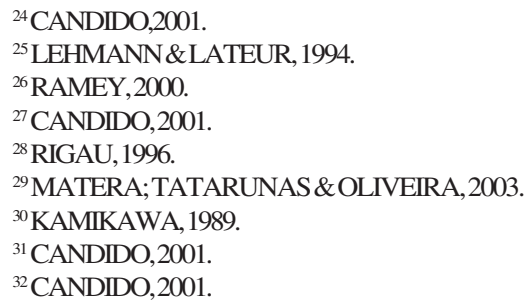

Univ. Ci. Saúde, Brasília, v. 3, n. 2, p. 275-286, jul./dez. 2005 
e auxilia a eliminação de corpos estranhos e de material desvitalizado, por meio do estímulo dado à microcirculação local ${ }^{33}$. A melhora na vascularização é observada com o uso da laserterapia, uma vez que sua ação no processo de neoformação vascular favorece a circulação sangüínea local e o processo de reparação tecidual e promove aceleração da cicatrização tecidual ${ }^{34}$.

Os aparelhos a laser podem ser compostos por vários gases, como o dióxido de carbono $\left(\mathrm{CO}_{2}\right)$, o diodo, o neodímio ( $\mathrm{Nd}$ ), o arseneto de gálio (AsGa) e o de hélio-neônio (HeNe), sendo esse último o mais empregado no processo de reparação de tecidos lesados ${ }^{35}$. Os equipamentos de laser hélio-neônio mais utilizados são constituídos por um tubo longo; em seu interior, encontram-se esses gases naturais em baixa pressão, envoltos por mecanismo disparador de flash, que, quando acionados, excitam os átomos dos gases liberando quantidades crescentes de energia que liberam fótons direcionados, os quais emergem como feixe estreito através da extremidade do tubo. O laser de hélio-neônio emite radiação na região de radiação visível vermelha com comprimento de onda de $632,8 \mathrm{~nm}^{36}$.

O laser terapêutico tem efeito cicatrizante sobre o tecido cutâneo uma vez que age sobre a matriz colágena, acelerando a produção de fibras colágenas e a reparação tecidual. Em estudo feito por Reddy et al, 1998, comprovou-se que a aplicação de laser de $\mathrm{He}-\mathrm{Ne}$ em lesões provocadas em ratos levou a aumento de até $26 \%$ das fibras colágenas quando comparadas com o grupo controle.

\section{Técnicas de aplicação a laser}

A técnica de aplicação a laser varia conforme as características das feridas, levando-se em conta o aspecto do leito e, principalmente sua dimensão ${ }^{37}$. A radiação laser é, geralmente, aplicada na pele com uma caneta aplicadora cujo tamanho aproximado é de uma caneta esferográfica larga. A aplicação direta sobre a pele promove máxima transferência de energia laser para o tecido cutâneo ${ }^{38}$. Dessa forma, a aplicação tem melhor ação sobre o tecido irradiado.

Nas lesões pequenas, a aplicação deve ser feita diretamente sobre a área lesionada. No caso de feridas extensas, com áreas largas, a lesão pode ser dividida em quadrantes de cerca de $2 \mathrm{~cm}$ quadrados, e cada porção é irradiada separadamente. Outra forma de aplicar o laser é mover a caneta continuamente sobre a

\footnotetext{
${ }^{33}$ TAVARES, 2002.

${ }^{34}$ ROIG, etal.

${ }^{35}$ CANDIDO, 2001.

${ }^{36}$ LOW \& REED, 2001.

${ }^{37} \mathrm{CÂNDIDO}, 2001$.

${ }^{38}$ LOW \& REED,2001.
} 
superfície da ferida em técnica conhecida como varredura. A fonte emissora de irradiação laser deve ser mantida afastada a alguns centímetros da lesão para que se evite contaminação da ferida ${ }^{39}$.

\section{Dosagem}

Uma das muitas incertezas sobre os efeitos terapêuticos da radiação laser pairam sobre a dosagem ideal a ser utilizada durante as aplicações. Nas pesquisas científicas, tanto os valores de comprimento de onda quanto os de densidade de energia variam, não se encontrando uniformidade. Para Low \& Reed, 2001, o laser vermelho deve ser utilizado em condições superficiais já que seu comprimento de onda promove mínima penetração da irradiação nos tecidos, sendo indicado para o tratamento de lesões superficiais, como, por exemplo, úlceras de pressão.

\section{Considerações finais}

Há muito tempo, as úlceras de pressão têm sido sinônimo de complicações para aqueles pacientes que permanecem muito tempo imobilizados em leito ou em cadeiras de rodas. A literatura mostra que medidas simples são suficientes para evitar esse problema que, a cada ano, atinge milhares de pessoas. A prevenção ainda é a melhor forma de combate às úlceras de pressão, bastando, para tanto, melhor treinamento daqueles profissionais da área de saúde que convivem com o problema dia-a-dia e maior esclarecimento da população em geral a respeito do assunto. Tratamentos mais eficazes podem ser implementados, por meio de novas pesquisas, no desenvolvimento de novos dispositivos que possam aliviar a pressão de forma mais eficiente, medicamentos tópicos que controlem melhor os focos de infecção nas feridas já instaladas e, principalmente, estudos mais detalhados e mais confiáveis sobre o verdadeiro potencial de medidas fisioterápicas, como a laserterapia no tratamento desse tipo de lesão.

\section{Referências}

BLANES, L. Tratamento de feridas. In: BAPTISTA-SILVA JCC (ed.). Cirurgia vascular: guia ilustrado. São Paulo: 2004.

BRYANT, R. A., et al. Pressure ulcers. In: BRYANT, R. A., Acute chronic wounds: nursing management. St. Louis: Mosby - Year Book, 1992. p. 105 - 159.

${ }^{39}$ LOW \& REED, 2001.

Univ. Ci. Saúde, Brasília, v. 3, n. 2, p. 275-286, jul./dez. 2005 
CANDIDO, L.C: Nova abordagem no tratamento de feridas.

São Paulo: SENAC, 2001.

COSTA FILHO, R. M., et al. Laserterapia no tratamento das úlceras compressivas: relato de caso. In: Semina, Londrina, v.15, n.2, p.171-174, jun. 1994.

DEALEY, C. Cuidando de feridas: um guia para as enfermeiras. São Paulo: Atheneu, 1996.

KAMIKAWA, K. Studies on low power laser therapy of pain. In: Laser Dentistry 1989; 12: 29-38.

LOW, J., REED, A. Eletroterapia explicada: princípio e prática. 2.ed. São Paulo: Manole, 2001.

MATERA, J.M., TATARUNAS, A.T., OLIVEIRA, S.M. Uso do laser de arseneto de gálio (904nm) após excisão artroplástica da cabeça do fêmur em cães. In: Acta Cirúrgica Brasileira 2003; 18: 102-103

MONETTA, L. Uso da papaína nos curativos feitos pela enfermagem. In: Rev Bras Enf 1987; 40 (1): 66-72.

RAMEY, D. W., BASFORD, J.R. Laser Therapy in horses. In: Comp. Cont. Educ. 2000; 22: 263-71.

REDDY, G.K., STEHNO-BITTEL, L. , ENWEMEKA, C.S. Laser photostimulation of collagen production in healing rabbit Achilles tendons. Lasers in Surgery and Medicine.1998; 22: 281-87.

ROIG, J.L.G. et al. Tratamento de las úlceras por préssion em el lesionado medular com laser de baja potencia y cirurgia. Presentation de um caso. In: Rev. Cuba Ortop. Traumatol. 1990; 4: 41-5.

SANCHEZ, N. R, et al. Aspectos morfológicos e morfométricos da reparação tecidual de feridas cutâneas de ratos com e sem tratamento com solução de papaína a $2 \%$. In: Acta Cirúrgica Brasileira 1993;8(1):18-23.

SILVA, L.M. Efeitos benéficos da papaína no processo terapêutico de lesões de pele. In: JORGE S.A., DANTAS S.R.P.E. Abordagem multiprofissional no tratamento de feridas. São Paulo: Atheneu; 2003. p.123-31.

SMELTZER, S. C., BARE, B. G. Brunner \& Suddarth: tratado de enfermagem médicocirúrgica. 7.ed. Rio de Janeiro: Guanabara Koogan, 1994.

TAVARES, M.R. Efeito do laser terapêutico na cicatrização tendinosa: estudo experimental em ratos. Tese de dissertação de pós-graduação Ribeirão Preto 2002

YAMADA B.F.A. Terapia tópica de feridas: limpeza e desbridamento. In: Rev Esc Enf USP 1999;33:133-40.

(http://www.eerp.usp.br/projetos/ulcera/index.html), acesso em 05/09/2005.

(http://www.feridologo.com.br/fculceras.htm), acesso em 12/09/2005.

(http://www.manualmerck.net/?url=/artigos/\%3Fid\%3D223), acesso em 20/09/2005. 